\title{
Towards a Better Tourist-Host Relationship: The Role of Social Contact between Tourists' Perceived Cultural Distance and Travel Attitude
}

\begin{abstract}
The ambiguous effect of cultural distance on travel attitude and tourist behaviours has long been debated, but its implications are vital to the success of achieving a sustainable touristhost relationship. The study explored the direct and indirect effects of perceived cultural distance on travel attitude by adopting a mixed-methods approach and introducing a multi-dimensional perspective regarding the tourists' social contact with the local. The mediating role of touristhost social contact was also confirmed. The study found that the relationship between perceived cultural distance and travel attitude is 'contact elastic'. Results empirically support the coexistence of the paradoxical effects of cultural distance on travel attitude. Implications are provided to policy-makers, practitioners and local communities regarding achieving a sustainable tourist-host bond.
\end{abstract}

Keywords: social contact, perceived cultural distance, travel attitude, tourist-host relationship, social sustainability 


\section{INTRODUCTION}

Tourism brings people from diverse cultural backgrounds into contact with each other, and such communication builds a mutual appreciation of their viewpoints, which leads to understanding, respect and liking each other (Allport, 1979; Fulbright, 1976). However, cultural shock engendered from interactions with the hosts may generate uncertainty and panic, which may lead to negative perception towards the destination (Goeldner \& Ritchie, 2008; Lepp \& Gibson, 2003; Ward, Bochner \& Furnham, 2005). Cohen (1972) highlighted that the communication gap, such as language, can intensify the isolation of the mass tourist from the host society. The incoherence in the literature leaves the relationship between perceived cultural distance and travel attitude a mystery and calls for empirical investigation of this contradiction from diverse perspectives.

Culture is a key component to understand and unveil the intricate intergroup relationship. Considering Cohen's (1972) and Jaakson's (2004) tourist bubble, social separation acts like a bubble, creating a protective wall for tourists in the host communities (Smith, 1989; Ward et al., 2005). Within this wall, tourists travel with their original culture, perceive things through their cultural lens and behave with their cultural standards and judgments in mind. Though abundant studies have explored the concept of culture and cultural distance (Caulkins 1999; Hofstede, Hofstede \& Minkov, 2010; Triandis, 1994), a convincing explanation of the dynamic cultural effects on tourists' behaviours and perceptions are still absent.

The social contact between tourists and residents can influence tourists' positive perception of their destinations and the residents by boosting mutual understanding, eliminating bias and stereotypes and enhancing intergroup relations (Allport, 1979; Binder et al., 2009; Kawakami et al., 2000; Kirillova, Lehto, \& Cai, 2015; Pettigrew, 1998). By contrast, social contact can lead to negative perception by increasing intergroup tension, hostility and suspicion 
between tourists and hosts (Bochner, 1982; Pizam, Uriely, \& Reichel, 2000). Although touristhost social contact has strong predictive power on tourists' perception towards their trips, a limited number of studies have investigated the tourist-host social contact's effect on tourists' travel attitude (Fan, Zhang, Jenkins \& Lin, 2017). Less attention has been paid to its role in interpreting the relationship between tourists' perceived cultural distance and travel attitude. In addition, as stated by Tasci (2009) and Joo et al. (2018), the directional relationships between distance and tourist behaviours, including tourist-host interactions and visit intentions, can be a 'chicken and the egg' situation or a case of concurrently existing human phenomena. Cultural distance and social contact hence tend to influence and reinforce each other concurrently. However, most of the existing studies investigating the relationship between cultural distance and social contact put cultural distance as an outcome of social contact (Aleshinloye et al., 2020; Joo et al., 2018; Yilmaz \& Tasci, 2015). The effect of tourists' perceived cultural distance on their social interactions with the local people in the destination is largely overlooked.

This study investigates from a tourist perspective and aims to bridge the abovementioned research gaps by exploring how tourists' perceived cultural distance and social contact with the host can influence their travel attitude towards a destination. The specific research objectives are 1) to explore the direct relationships among perceived cultural distance, tourist-host social contact and travel attitude and 2) to examine the mediating effect of tourist-host social contact in the relationship between perceived cultural distance and travel attitude by building on those direct relationships. 


\section{THEORETICAL BACKGROUND}

\section{Cultural distance and travel attitude}

Culture holds a broad range of interpretations, including knowledge, belief, custom and habits that influence individuals' ways of selecting, understanding, processing and using the information they receive (Triandis, 1994). Cultural distance is defined as the extent to which the culture of the original region differs from the culture of the host region (Goeldner \& Ritchie, 2008). Cultural distance represents the differences among groups of people who perform activities and perceive the world differently (Potter, 1989).

As culture holds a wide range of understanding, different scholars may have a different understanding of their studies, and the measurement of cultural distance varies accordingly in different research topics and settings. For example, Hofstede's cultural dimensions theory provides a framework with six value dimensions for measuring national culture, including power distance, individualism-collectivism, masculinity-femininity, uncertainty-avoidance, long-term orientation and indulgence-restraint (Hofstede et al., 2010). Hofstede's cultural dimensions are widely applied in tourism research in relation to tourism demand (Ahn \& McKercher, 2015; Fan, Liu \& Qiu, 2017), choice of destination (Esiyok, Çakar \& Kurtulmuşoğlu, 2017) and acculturation process (Mazanec, Crotts, Gursoy \& Lu, 2015). Grid-group cultural theory claims that people can be classified into four major social types, namely, individualists, fatalists, hierarchists and egalitarians (Caulkins 1999; Douglas 1982; Li et al. 2015). For cultural differences from the perspective of tourists, Wei, Crompton and Reid (1989) stated that elements, such as accommodation, food and level of hygiene could lead to cultural conflicts that generate varying perceptions of what constitutes appropriate behaviour. In addition, Reisinger and Turner (1998a, 1998b, 2002a, 2002b) reported that cultural values, rules of social behaviour, 
perceptions, social (tourist-host) interaction and satisfaction are essential dimensions that reflect the cultural differences between Western hosts and Asian tourists. Fan et al. (2017b) developed a three-dimensional measurement scale of perceived cultural distance from a tourist's perspective. The measurements of perceived cultural distance include cultural retention, behavioural and social characteristics. This set of measurements captures tourists' perceived cultural distance encountered in travel, rather than measurements generated or adopted from other disciplines. Similarly, Lee et al. (2018) identified social environment, personal relationship, living arrangements and verbal communication as four dimensions of mainland Chinese tourists' perceived cultural distance when traveling to Taiwan.

Attitude represents individuals' tendency to evaluate symbol, object or perspective of the world favourably or unfavourably (Azjen, 1991; Mayo \& Jarvis, 1981). Attitude has also caught considerable attention from scholars. Attitude is a reliable indicator of how people act given a set of conditions in different styles of life. In the context of tourism, travel attitude is the predisposition or feeling towards a travel destination or service, and is based on multipleperceived product attributes (Hsu \& Huang, 2012; Moutinho, 1987). Attitude can be multidimensional. Rosenberg, Hovland, McGuire, Abelson and Brehm (1960) proposed the three components in attitude, namely, cognitive, affective and behavioural (Mayo \& Jarvis, 1981). The cognitive component refers to beliefs based on tangible evidence perceived as fact by an individual at a given time spot. Affective component is the emotional judgment an individual makes towards an object. The behavioural component describes the tendency to respond favourably or unfavourably to a certain object. Furthermore, the single-dimensional attitude has been adopted predominantly in tourism research. Most tourism studies believed that attitude is a single-dimensional construct that represents the affect for or against a psychological object, 
event or situation (Bagozzi \& Burnkrant, 1979). This assumption is implemented in the Theory of Reasoned Action (TRA) (Fishbein \& Ajzen, 1975) and the Theory of Planned Behaviour (TPB) (Ajzen, 1988), which are fundamental theories for ample research in different disciplines, including tourism (Hsu, Kang \& lam, 2006; Lam \& Hsu, 2006).

Cultural distance is reported to have negative and positive effects on travel attitude in different studies. From a distance decay perspective, cultural distance may affect tourists' inclination to travel to a certain destination negatively. The negative effect of cultural distance is found on international tourist flows (Liu, Li, Cárdenas \& Yang, 2018; Yang, Liu, \& Li, 2018). People sought differences and changes when travelling to the extent that differences and changes remain non-threatening (Cohen, 1979). Goeldner and Ritchie (2008) concluded that the larger the cultural distance between the tourist origin country and the destination, the greater the resistance to travel to that destination.

Moreover, cultural differences in areas, such as food, language, cleanliness, the pace of life, recreation, the standard of living, humour, intimacy and privacy etiquettes are often associated with stress, even though the travel purpose is for relaxation or sight-seeing (Leung, Woo \& Ly, 2013; Martin, Jin \& Trang, 2017; Spradley \& Philips, 1972). Ng, Lee and Soutar (2007) adopted five different cultural distance measures and argued that the greater the perceived cultural similarity of a foreign destination to Australia, the more likely for Australians to visit a destination. Therefore, people will have a positive attitude towards others with similar cultures (Moufakkir, 2011). All the research suggests the greater the cultural distance between a destination and a tourist's home country, the more negative the tourist would feel towards the destination. 
This argument has been challenged by studies in tourist motivation. Travel motivation has been examined as a good predictor for travel attitude in various research contexts (Ajzen, 1991; Hsu, Cai, \& Li, 2010; Hung \& Petrick, 2011). In travel motivation studies, cultural novelty-seeking/discovery is one of the highly ranked items that inspire tourists to travel (Beard \& Ragheb, 1983; Crompton, 1979; Dewar, Meyer, \& Li, 2001; Hsu et al., 2010; Ragheb \& Beard, 1982; Ryan \& Glendon, 1998) and has a significantly positive effect on tourists' attitude towards a destination (Hsu et al., 2010). In that case, cultural distance rather than cultural similarity can arouse tourists' positive travel attitude. A destination's cultural features are also associated with destination choice (McKercher \& Cros, 2003). McKercher and Chow (2001) argued that the greater the cultural difference, the more likely that tourists would participate in cultural activities and the more important cultural attributes are in their destination decisionmaking process.

According to existing literature, this study aims to test such relationship in the social contact context. Therefore, Hypothesis 1 can be derived as follows:

H1a: Perceived cultural distance is positively related to travel attitude.

H1b: Perceived cultural distance is negatively related to travel attitude.

\section{Tourist-host social contact and travel attitude}

Cross-cultural social contact is the contact between individuals from different cultural contexts (Cusher \& Brislin, 1996; Yu \& Lee, 2014). Tourist-host social contact is perceived as a unique type of cross-cultural contact due to tourists' short and well-structured time, purposes of travel and poor adaptation to the local community (Barthes, 1973; Pearce, 1982). 
The concept of social contact has been explored and measured from different perspectives. Activities (Mo, Howard \& Havitz, 1993; Reisinger \& Turner, 2002a and b; Rothman, 1978) and frequency (Woosnam \& Aleshinloye, 2013) of social contact were applied as the only measurements of social contact. Other research considered multiple dimensions to measure the social contact experience. For instance, Huang and Hsu (2010) examined the activity, frequency, influence, valence, intensity, power and symmetry of customer-to-customer interaction on cruises. Fan et al. (2017b) developed a tourist-host social contact scale from a tourist viewpoint. The measurements included three dimensions, namely, social- and service-oriented contact and quality of contact. Items in social- and service-oriented contact measured the quantity of social contact and each contact activity was rated by the degree of frequency a tourist had with hosts, from a range of 'never' to 'very frequently'. This scale considers the quantity (i.e. social- and service-oriented contact activities) and quality aspects of contact. The quantity of contact is categorised into social- and service-oriented aspects, which could distinguish various effects from different contacts. In addition, considering activity and its corresponding frequency together allows a precise way to evaluate the effect caused by individual activity.

Existing literature has explored the effects of social contact on tourists' travel attitude; however, no agreement has been achieved. As a conventional understanding, contacts between two parties can bring a positive attitude towards each other. Allport's (1979) contact theory proposed that contacts may offer ways to minimise stereotyping and discrimination between two culturally different regions under certain conditions, such as with common goals, equal status and sanctioned support (Yu \& Lee, 2014; Joo et al., 2018). Contact theory in social psychology provides a general idea of the outcome of international encounters. In the context of tourist and host relationship studies, social contact between the two groups enhances positive attitudes and 
mutual understanding toward each other (Amir \& Ben-Air, 1985; Carneiro \& Eusébio, 2015; Pearce, 1982; Pizam et al., 2000). For instance, the social contact has a significant effect on the resident's perceptions of the effects of tourism on the quality of life (Carneiro \& Eusébio, 2015; Carneiro, Eusébio \& Caldeira, 2018) and the attitude towards tourists (Joo et al., 2018). For tourists, the contact with the local can lead to a positive travel experience in the destination (Li \& Liu, 2020). Compared with long-lasting kinds of contact, contact between groups through tourism will need to accumulate, diversify, and deepen to achieve a positive change in intergroup attitudes and behaviour (Yilmaz \& Tasci, 2015). The same attitude towards the hosts can be spread to their attitude towards the travel destination (Fan, Zhang, Jenkins \& Tavitiyaman, 2017; Pearce, 1982; Pizam et al., 2000).

The above popular belief has been challenged by empirical studies, which argue that intergroup contact does not necessarily reduce intergroup tension, prejudice, hostility and discriminatory behaviour (Anastasopoulos, 1992; Milman, Reichel, \& Pizam, 1990; Pizam, Jafari, \& Milman, 1991). The contact results depend heavily on the contact conditions between the two sides as concluded previously in contact theory (Pizam, 1996; Thyne, Lawson \& Todd, 2006). The negative effect may result from the unique nature of social contact in tourism. During the relatively short time of visit, the limited and shallow contacts between two culturally different parties may induce communication difficulties and increase tension, hostility and suspicion (Nyaupane, Timothy \& Poudel, 2015). For instance, cross-cultural voluntourism is argued to reinforce negative perceptions between tourists and local recipients, as many voluntourists consider local recipients as 'inferior' or 'less-able' (Sin, 2009; Woosnam \& Lee, 2011). Under such context, the greater the social contact, the more likely the negative attitude will be triggered towards the hosts and the destination. 
To address the contradictory relationship between tourist-host social contact and travel attitude as indicated in the literature, Hypothesis 2 is established as follows:

H2a: Tourist-host social contact is positively related to travel attitude.

H2b: Tourist-host social contact is negatively related to travel attitude.

\section{Perceived cultural distance and tourist-host social contact}

Tourists undoubtedly constitute the largest group of cross-cultural experiencers. The effects of cultural attributes on tourist-host contact depend largely on the degree of cultural similarity and difference between contact participants (Levine, 1977). Cultural similarity leads to mutual understanding, sense of familiarity and social interaction among individuals (Brewer \& Campbell, 1976; Feather, 1980; Lin, Fan, Zhang \& Lau, 2019). A positive relationship is found between culture similarity and socialisation (Siehl \& Martin, 1985). Meanwhile, cultural dissimilarity distorts the meanings of the behaviour (Triandis, 1977), results in communication difficulties and emotional detachment (Fan et al., 2017a), as well as inefficient social contact (Robinson \& Nemetz, 1988). In that case, future interaction may even be lost (Kamal \& Maruyama, 1990; Fan et al., 2017a).

Based on the existing literature, Hypothesis 3 is proposed as follows:

H3: Perceived cultural distance is negatively related to tourist-host social contact. 


\section{Mediating role of social contact}

Considering the relationship between perceived cultural distance and social contact, and that between social contact and travel attitude, social contact may serve as the mediator between perceived cultural distance and travel attitude. In one circumstance, perceived cultural distance has a negative effect on travel attitude by restricting effective interactions with the locals. Tourists travelling to a destination with large perceived cultural distance are encapsulated by their culture and tend to have limited interactions with the hosts because of communication obstacles or psychological uncertainty (Cohen, 1972; Fan et al., 2017a). In that case, tourists do not obtain the chance to understand the locals, which would lead to a negative travel attitude. According to staged authenticity (Cohen, 2007; MacCannell, 1973), perceived cultural distance can ensure that tourists engage in well-designed and non-threatened contacts with well-trained destination representatives, such as service staff. The trained staff can prevent tourists from encountering disappointing, misunderstood and unexpected contacts with the hosts induced by the cultural shock. As a result, tourists may generate positive travel attitude. To demonstrate this relationship, Hypothesis 4 is proposed as follows:

H4: Tourist-host social contact mediates the relationship between perceived cultural distance and travel attitude.

Upon the formation of all the hypotheses, the theoretical model of this study is established and shown in Figure 1.

\section{Insert Figure 1 Here}




\section{METHODOLOGY}

\section{Research context}

This study selected Hong Kong tourists travelling to mainland China as the research context, based on the remarkable tourist flow, cultural bond, differences, and residential contact between the two regions. The 100 years of colonisation by the UK and separation from mainland China has made Hong Kong and mainland China ethnically similar but ideologically different regions. The cultural, historical and political connections, as well as differences between the two regions, have gained considerable attention in academic and non-academic domains. Moreover, several recent incidents in Hong Kong, such as the 2014 Umbrella Revolution and 2019 protests, reflect the urgency and practicality of understanding the relationship between Hong Kong and mainland China. With the high tourist flow in both directions, contacts between tourists and hosts at the individual level can be massive and important to the relationship between the two regions. The urgent need for understanding the role social contact plays in achieving a sustainable relationship between tourists and hosts makes this an ideal case for the current study.

\section{Questionnaire and interview protocol development}

The mixed-methods approach was used to achieve a set of research objectives from different perspectives. The quantitative approach was applied to examine statistically the structural model proposed by research objectives 1 and 2 . The complicity of the model and the sensitivity of the cultural distance and social interactions between Hong Kong tourists and mainland Chinese hosts places the mechanism of how the social contact moderates the relationship between cultural distance and travel attitude beyond statistical indices. Therefore, the qualitative approach was used to understand further the underlying reasons for those proposed relationships. 
In the quantitative approach, a survey was carried out to test statistically the hypotheses and the structure of the proposed model. Before the questionnaire design, the measurement instruments for the three constructs were selected and justified. In this study, the measurements of perceived cultural distance and tourist-host social contact were adopted from Fan et al.'s (2017b) work, which was a mixed-methods study and shared the same research context as the current one, i.e., Hong Kong tourists travelling to mainland China. The measurements of travel attitude were adopted and further consolidated from a series of attitude studies (Han et al., 2010; Hsu et al., 2010; Lam \& Hsu, 2006; Sparks \& Pan, 2009; Wang \& Ritchie, 2012).

Besides perceived cultural distance and tourist-host social contact, several variables relating to travel patterns and experiences needed to be controlled in this model because of the potential effects on travel attitude (Poon \& Huang, 2017). Travel patterns, such as length of stay, frequency of travel and travel mode (individual or package tour travellers) may affect tourists' perceptions and behaviours during their trips (Chen et al., 2016; Sung et 1., 2001; Thrane, 2016; Zhang \& Lam, 1999). Moreover, in the current research context, which is Hong Kong tourists travelling to mainland China, respondents' immigration background tended to have a strong effect on their cultural perceptions and their social behaviours in the destinations because of the considerable number of immigrants from mainland China to Hong Kong. People who have immigration background from mainland China may have a better understanding of the culture of the destination and a stronger connection to the destinations than Hong Kong tourists who have no such background (Shen, Luo \& Zhao, 2017; Ye et al., 2014). Therefore, length of stay, frequency of travel, travel mode and immigration generation are set as the control variables for the current model. 
The questionnaire included four parts. The first part comprised screening questions that aimed to select the qualified respondents for the current study. In this study, respondents should be Hong Kong permanent residents and have travelled to mainland China for leisure purposes in the last two years. The second part contained trip-related questions, which aimed to seek respondents' travel patterns and personal experiences. The third part included 41 five-point Likert-type scale questions measuring the three constructs in the proposed framework. The last part of the questionnaire was for the demographic questions. Questions were set to obtain the profile and social characteristics of the respondents. The original questionnaire is provided in Appendix 1. The questionnaire was originally designed in English. For convenient distribution to Hong Kong residents, the questionnaire was translated into traditional Chinese by back-translation technique. After obtaining the quantitative result, semi-structured in-depth interviews were conducted to collect the tourists' insights regarding the rationale of the quantitative results. The qualified respondents for the current interview are permanent Hong Kong residents who have travelled to mainland China for leisure purposes in the past two years. Questions were designed to reflect the different concepts and relationships proposed in the conceptual model. First, to warm up interviewees to the topic, they were asked on their travel experiences to mainland China. Second, after the warmup, interviewees were requested to evoke any memories of perceived cultural distance and social interactions with the locals they may have encountered during their travel. Third, interviewees were asked to share their overall attitude towards the trip with examples. To correspond to specific relationships in question, informants were then asked if they experienced any impact of perceived cultural distance on tourist-host social contact and travel attitude. If yes, they were asked how they thought the effect might work. Lastly, questions were also asked regarding the effects of tourist-host social contact on travel attitude. Respondents' demographic 
data, including age, gender, education, occupation, personal monthly income and marital status, were collected at the end.

\section{Sampling and data collection}

In terms of the survey, Shanghai, Beijing, Hangzhou and Chongqing, were the top four destination cities for Hong Kong overnight travellers to Mainland China between 2012 and 2016 and were selected to as data collection spots for quota sampling purpose (CNTA, 2017). Considering a large number of migrants in Hong Kong are from Guangdong and Fujian provinces in mainland China, cities in the two provinces were excluded from this study to avoid potential cultural similarity issue. According to the market share of the top four destination cities, the quota of Shanghai and Beijing was set to 250 and 150, respectively, whereas Hangzhou and Chongqing were 100 each. The proposed sample of 600 was large enough to run the model with a reliable and valid outcome (Hair, Black, Babin, \& Anderson, 2010). The research team collected data from October 2015 to February 2016 in the departure hall of the airport in each selected city, during low and high seasons. As a result, 660 valid samples were collected from Shanghai (250), Beijing (155), Hangzhou (145) and Chongqing (110).

A total of 22 semi-structured interviews were conducted to permanent Hong Kong residents with travel experience to mainland China for leisure purposes in the last two years. Convenience sampling was applied. The interviews were carried out using the interviewees' native language and each interview lasted for 26 to 88 minutes. New interviewees were not invited when the information collected was saturated. The transcripts were translated into English with the assistance to two professional language editors specialising in Cantonese and English. 


\section{Data analysis}

Partial least squares structural equation modelling (PLS-SEM) was selected to estimate the models. PLS-SEM has advantages in dealing with complex models (i.e. three mediating hypotheses testing) and formative relationships (i.e. second-order structure) (Hair, Ringle, \& Sarstedt, 2011; Henseler, Hubona, \& Ray, 2016). Samples with missing values were deleted due to the requirements of PLS-SEM. Thus, 635 valid responses were retained. For the measurement model, confirmatory factor analysis (CFA) was performed to confirm the dimensionality and structure of each factor. Reliability and validity were also tested. In the structural model, SEM was conducted to examine the relationships in the model. Bootstrapping, which is a resampling method, was used to examine the significance of the mediation effects. Bootstrapping involves repeatedly randomly sampling observations with replacement from the data set to compute the desired statistic in each resample. Computing over bootstrap resamples provide an approximation of the sampling distribution of the statistic of interest. Based on the computed sample mean and standard deviation, t-statistics can be calculated to determine the significance of the mediating effect.

Textual data derived from the transcripts were interpreted and analysed with thematic analysis, which focused on exploring themes within data and emphasised the rich description of the data set (Daly, Kellehear, \& Gliksman, 1997). Thematic analysis engages a process of categorising and grouping textual data to explore the emerging meaning relevant to the current two research objectives (Braun \& Clarke, 2006). Software NVivo 11 was applied to code the transcripts technically. Considering the principles, during coding, meaningful units in participants' transcripts were captured and utilised to formulate key themes regarding the tourists' perceptions 
towards the concepts and their interrelationships as proposed in the model. Therefore, two themes covering both direct and indirect relationships are proposed in the research model. Within the direct relationship, the three sub themes included the relationship between cultural distance and travel attitude, tourist-host social contact and travel attitude as well as cultural distance and tourist-host social contact. Investigator triangulation was also applied to ensure the trustworthiness of the qualitative result (Lincoln \& Guba, 1985). All authors regularly conducted intra-team communication and coding structure comparison during data analysis to ensure accuracy and credibility of the results. Inter-rater reliability was used to check the interrater agreement scoring of all the themes across all raters. As a result, the index was $87 \%$, which was deemed satisfactory (Tran \& Ralston, 2006).

\section{FINDINGS}

\section{Quantitative data analysis}

Respondents' demographic information and travel patterns are indicated in Table 1. Among the 635 respondents, $56.98 \%$ were male. Respondents accounting for $34.13 \%$ were in the age group of 45 to 64 years old, followed by 35 to $44(27.11 \%)$ and 25 to 34 (23.92\%). Two-thirds of the respondents held a bachelor's degree or above, and one-third of them had a monthly household income of $60,000 \mathrm{HKD}$ or above. The majority (85.67\%) worked in non-tourism related industries. Around 33\% of respondents categorised themselves as managers or administrators, and $30 \%$ as professionals. Over half $(52.8 \%)$ were married with child(ren).

In terms of the respondents' connections to the tourist destination, $31.26 \%$ lived in mainland China. Moreover, $12.91 \%$ were the first generation to immigrate to Hong Kong and $38.9 \%$ immigrated to Hong Kong following their parental generation. Regarding their current 
trips to mainland China, the majority travelled individually (79.37\%) and stayed for three to five days $(64.25 \%)$. In their lifetime, close to one third were frequent travellers who visited mainland China for more than 20 times and $23.46 \%$ travelled to mainland China up to three times. The demographic information of respondents was compared with a survey of Hong Kong travellers to mainland China conducted by the Hong Kong Census and Statistics Department (2015) to ensure the representativeness of the sample. The comparison revealed the two samples had similar proportions regarding gender, age and mode of tours, which indicates good representativeness of the sample.

\section{Insert Table 1 Here}

\section{Measurement model}

Before any other statistical tests, the descriptive statistics of the 41 items, including mean, standard deviation, kurtosis and skewness values are presented in Appendix 2. The reliability and validity of PLS-SEM are not subject to the distribution of the data and thus, the results of the current study would be unbiased. In the measurement model, CFA was conducted to evaluate the adequacy of the measurements. In this model, as perceived cultural distance included subconstructs, the current measurement model should be confirmed by the second-order CFA. One of the main objectives of this study was to examine the mediating role of tourist-host social contact, and thus, three dimensions were considered individually to obtain their separate mediating effects. Four items were deleted due to low factor loadings of below 0.4. These items were 'People in mainland China and Hong Kong have different cuisines' and 'People in mainland China and Hong Kong have different views on restrictions of freedom' from Perceived Cultural Distance construct and 'Interaction with the service personnel during tours (e.g. tour 
guides, bus drivers)' and 'Interaction with the locals during leisure activities' from the touristhost social contact construct. Factor loadings for the remaining 37 items equalled to or exceeded 0.695. Table 2 indicates the results of reliability and validity tests of the measurement model, as requested for the CFA model reporting (Assaker, Huang \& Hallak, 2012; Rasoolimanesh, Ringle, Jaafar \& Ramayah, 2017). In PLS, the reliability was examined by the composite reliability and $\rho_{A} s$. The composite reliabilities were all above 0.810 and the $\rho_{A} s$ were all above 0.659, indicating an acceptable reliability level (Bagozzi \& Kimmel, 1995). Construct validity was examined by convergent and discriminant validity. Convergent validity was examined by the value of AVE for each construct. The results showed that all AVEs were beyond the threshold of 0.5 , thereby meeting the ideal AVE for a well-developed construct (i.e. equal to or above 0.5) (Hair et al., 2010). Hence, convergent validity was established (Aleshinloye et al., 2020; Hair et al., 2010). The differences between constructs were examined using discriminant validity (Byrne, 2010), which monitors the external dissimilarity among factors (Hung \& Petrick, 2011). Discriminant validity was assessed by the heterotrait-monotrait ratio of correlations (HTMT). As shown in Table 3, all the HTMTs were significantly less than the unit at 5\% significant level, with all HTMTs between the two constructs below 0.9 , thereby representing a satisfactory validity level (Fan, Hsu \& Lin, 2020; Henseler et al., 2016).

\section{Insert Table 2 and Table 3 Here}

\section{Structural model}

Table 4 shows the results of the path analysis and hypotheses testing in the structural model. The first essential criterion for assessing a PLS structural equation model is $R^{2} \cdot R^{2}$ measures the relationship of a latent variable's explained variance to its total variance by the exogenous latent 
variables in the model (Assaker et al., 2012). The $\mathrm{R}^{2}$ of the structural model was 0.442 and the adjusted $\mathrm{R}^{2}$ was 0.435 , which indicated a good explanatory power of this model. Among all the seven paths, six paths were significant, indicating significant effects from the exogenous constructs to their corresponding endogenous constructs. In particular, perceived cultural distance had positive effect on travel attitude (coefficient $=0.067, \mathrm{p}=0.037$ ); service-oriented contact had positive effect on travel attitude (coefficient $=0.091, \mathrm{p}=0.038$ ); quality of contact had a strongly positive effect on travel attitude (coefficient $=0.628, \mathrm{p}=0.000$ ). Perceived cultural distance positively affected social-oriented contact (coefficient $=0.092, p=0.020$ ) and serviceoriented contact (coefficient $=0.155, \mathrm{p}=0.000)$, but negatively affected the quality of contact (coefficient $=-0.128, \mathrm{p}=0.002$ ). Social-oriented contact had no significant effect on travel attitude (coefficient $=0.002, \mathrm{p}=0.968$ ). Therefore, H1a was fully supported and $\mathrm{H} 2 \mathrm{a}$ and $\mathrm{H} 3$ were partially supported.

Regarding the mediating effect of tourist-host social contact in the structural model, the bootstrapping method was used to examine the existence of the mediation. As presented in Table 5, the direct effect of perceived cultural distance on travel attitude was significant and positive (coefficient $=0.067, \mathrm{p}=0.029$ ). The indirect effects mediated by tourist-host social contact varied across different contacts. The indirect effect mediated by social-oriented contact was not significant (coefficient $=0.000, \mathrm{p}=0.951)$ and the one mediated by service-oriented contact was positive (coefficient $=0.014, \mathrm{p}=0.016)$. On the contrary, the mediating effect of quality of contact was reported to be negative (coefficient $=-0.080, \mathrm{p}=0.001)$. In that case, the overall indirect effect by tourist-host social contact was negative (coefficient $=-0.066, p=0.011)$ and the total effect between the constructs of perceived cultural distance and travel attitude was not significant. Therefore, H4 was supported. 
Upon the completion of hypotheses assessment, a structural model with path coefficients and significant levels was drawn accordingly and presented in Figure 2. The figure indicated that the control variables, namely, length of stay, frequency of travel, travel mode and immigration generation, did not have significant effects on travel attitude.

\section{Insert Table 4, Table 5 and Figure 2 Here}

\section{Qualitative data analysis}

Interview transcripts were analysed to explore the relationship among perceived cultural distance, tourist-host social contact and travel attitude, and to supplement interpretive evidence for the model.

First, interviewees were asked on the effects of cultural distance on their social contact with the locals. Results revealed that perceived cultural distance can negatively affect the quality of contact, which led to an unpleasant contact experience. Most of the mentioned cultural distance was related to behavioural and social norms. As reported by Informant 10, 'Especially in some attractions, people are used to jumping the queue. This behaviour always creates quarrels with the locals' (Informant 10, female, 30-39, clerk).

'Some of the places are less developed compared with Hong Kong. People have a weak sense of hygiene. Seeing some men just pee on the side of the road is uncomfortable and do not need to be mentioned to the kids. I think it is just that area lacks proper education support' (Informant 5, female, 20-29, professional). 'I saw people spit everywhere....' (Informant 11, female, 40-49, clerk). 
However, differences in culture can also encourage social interactions between the tourists and hosts. Informants claimed they were amazed and attracted by the different lifestyles, traditional culture and socialisation practices in the destination and would like to interact with the locals to explore.

'People from the north are so different from us. They are more hospitable, warm-hearted and honest. I like to go to their local communities to explore more about their life. I visited the Beihai Park in Beijing once and found some senior people were writing on the ground with the water-inked Chinese brush pen. We never see that in Hong Kong. Those senior people noticed and chatted with us. They asked for our names and wrote our names with the water-inked Chinese brush pen for us, which was very impressive to us. They were very friendly and nice .... I think this city is very internationalised and tolerant to people from other places' (Informant 2, female, 30-39, hunting for jobs).

Second, in terms of the effects of social contact on tourists' travel attitude, results generally indicated a positive association between the two. More contacts with the locals could provide more opportunities for the tourists to cultivate a favourable and positive attitude towards the trip. As indicated by Informant 6,

'We stayed in a guest house and the house owner made our journey! As we would like to hire a car at the very last minute, no car was left. The owner was so kind as to give us a ride, no, it was a journey. He drove us around the small town and then down to the beach. I was so surprised that he seemed to know everyone. He introduced many different things to do here and we were so lucky as we did not make any travel plan. That trip was unforgettable' (Informant 6, female, 40-49, professional). 
I love to go to the local street markets, buying food and chatting with people when travelling. I can know what the local people are like, what they eat, and how they communicate with each other. That is the best place that you can get to know the local without any commercial cosmetics' (Informant 20, male, 50-59, early retirement).

Lastly, the mediating role of social contact in the relationship between perceived cultural distance and travel attitude was evident but showed contrary effects between quantity and quality of social contact. On the one hand, perceived cultural distance can lead to positive travel attitude by encouraging tourists' participation in various social contact in a destination.

'Experiencing different cultures is the main reason that I travel. I go to the local parks, try the authentic food and bargain in small shops. I get to know the local culture by chatting with people there. Then I find my trip very exciting' (Informant 20, male, 50-59, early retirement).

On the other hand, tourists who perceive large cultural distance with the hosts reported negative travel attitude towards the destination by generating a negative attitude towards the contact experiences with the hosts.

'One can easily get disappointed by the huge cultural shock. At least it is the case for myself. When you have a close experience with the so-called local thing, for example, loudly shouting at each other in a restaurant, unexpected (close) personal distance and ways of expression, I feel uncomfortable. Sometimes I prefer to travel within a small group of my people, so I can have my familiar environment with me and don't get shocked' (Informant 19, female, 60-69, retirement). 


\section{DISCUSSION AND IMPLICATIONS}

Considering indirect effects could offer alternative means to understand a relationship and provide insights to a broad body of knowledge due to the complex nature of tourist perceptions and behaviours. The current study explored the direct effect of perceived cultural distance on tourists' travel attitude and considered the mediating effect of tourist-host social contact in this relationship.

\section{Perceived cultural distance and tourist-host social contact}

Based on the data, perceived cultural distance has a negative effect on the quality of contact, but had a negative effect on the quantity of contact. According to the literature, differences in the cultural background may distort the meanings of expression and cause a decline in the efficiency and quality of interaction (Kamal \& Maruyama, 1990). The larger the cultural distance between the tourists and the hosts, the more negative the tourists perceive their contact experiences (i.e. hostile, superficial, clashing, unequal and competitive in quality of contact) with their hosts. However, cultural distance may lead to more contacts in terms of quantity between tourists and hosts regardless of the types of contact, which seems to be contrary to the literature (Fan et al., 2017a; Kamal \& Maruyama, 1990; Robinson \& Nemetz, 1988).

Interpretations can be derived from the literature and interviews. For the positive effect of quantity of contact because of cultural novelty seeking, tourists from a different cultural background would have the desire to explore the destination and the local culture by interacting with the hosts (McKercher \& Chow, 2001; McKercher \& Cros, 2003). The larger the cultural distance, the more the tourists are motivated to interact with the locals (Fan et al., 2017a). In that case, the tourists tend to contact a variety of local people for social and service purposes to know 
more about the destination. However, the more contact the tourists have, the more negative feelings are likely to be generated because of miscommunication and meaning distortion induced by the cultural difference (Fan et al., 2017a; Kamal \& Maruyama, 1990). To conclude, cultural distance enables tourists to contact as much as they like with the hosts, but the overall contact quality with the hosts is constrained by the cultural distance (Levine, 1977). The overlooking of the dimensionality of social contact from previous literature may lead to a simple and unstable homogeneity in different individual cases. Considering the quality and quantity aspects of social contact enables researchers to differentiate the opposite effects from different aspects.

\section{Tourist-host social contact to travel attitude}

In terms of the relationship between the tourist-host social contact and the travel attitude, the current study generally supported the positive association between the two constructs. The study extended Allport's (1979) contact theory to the tourism context and further examined the importance of contact conditions proposed in Allport's theory, which were largely overlooked by previous studies examining the outcomes of contacts. The result showed consistency with Allport's (1979) contact theory, which emphasises that intergroup contact can produce positive effect if such contact is under certain conditions, such as equal status, common goals, cooperation and personal interactions. Tourism, being described as a great force for peace and understanding, can provide an equal, cooperative, pleasant and personal environment, which may naturally nurture positive intergroup connections.

Concerning different dimensions of social contact, the quality of contact is reported to have a salient effect on travel attitude. The strong effect may result from the nature of this concept. Fan et al. (2017b) stated that tourists subjectively evaluate the quality of contact and 
travel attitude. Positive perception towards the contacts with the hosts may directly link to positive perception towards a destination. The affective association may overshadow tourists' objective judgment towards the two concepts (Huang \& Hsu, 2010). Regarding the quantity of contact, the service-oriented contact was positively related to tourists' travel attitude, whereas the social-oriented contact did not show any significant effect on travel attitude. In the serviceoriented contact, tourists' contact points are mostly the representatives of the tourist sectors (Cohen, 1972; MacCannell, 2018), including hotel service staff, tour guides, restaurants service staff and taxi drivers, as disclosed in the interviews. Such kinds of interactions result in relatively shallow contacts. Nonetheless, the contacts can be helpful and useful for tourists' trips in the short run and may leave a positive impression for the tourists due to the favourable nature (Zatori, Smith \& Puczko, 2018).

\section{Mediating role of tourist-host social contact}

As the most profound finding of the current study, the tourist-host social contact was found to be a mediator of the relationship between perceived cultural distance and travel attitude.

Interestingly, by adopting the three dimensions to measure the abstract concept of tourist-host social contact, different dimensions of tourist-host social contact played different roles in mediating the relationship. By participating in social contact in a destination, the positive effect of perceived cultural distance on travel attitude was significantly enhanced. However, due to the salient effect of quality of contact on travel attitude, tourists who perceived large cultural distance with the hosts may have negative travel attitude towards the destination by generating negative attitude towards the contact experiences with the hosts. Therefore, the overall mediating effect of tourist-host social contact turned out to be negative. 
As stated at the beginning of this paper, considering social contact may provide supplemental ways to understand the ambiguous relationship between cultural distance and travel attitude. When considering the direct effect per se, cultural distance positively affected tourists' travel attitude at a weak level. However, events that occurred beyond the direct relationship but eventually reflected on this relationship may not be as simple as the linear assumptions proposed in the literature. Social contact, together with many other potentially influencing factors, delivers an indirect effect, which may further reinforce or weaken the original effect. In this model, tourist-host social contact is reported to mediate negatively the relationship between perceived cultural distance and travel attitude. This negative effect further results from a positive mediating role of the quantity of contact (service-oriented social contact) and the negative mediating role of quality of contact. Due to the inconsistency between the direct and indirect effects, the total effect in this model between perceived cultural distance and travel attitude was positive but not significant. As can be deduced, social contact is merely one behaviour out of many others that can mediate the effect of cultural distance and travel attitude. Considering other attributes may lead to a different total effect between the two constructs.

In response to the fundamental research question, 'how does perceived cultural distance influence travel attitude?', suggestions can be drawn as follows. Perceived cultural distance influences tourist's travel attitude in diverse ways and can directly and positively affect travel attitude. Meanwhile, the perceived cultural distance may deliver a positive effect on travel attitude by participating in service-oriented social contact. However, perceived cultural distance can negatively affect tourists' travel attitude by generating negative contact experience with the hosts. 
Associating the findings of the current study with the existing literature, this study provided empirical support for the previous argument. In particular, scholars who held the belief that contacts between two parties with large cultural distances may lead to a negative attitude deemed that differences in cultural background induced cultural shock, perceptions of risk (Lepp \& Gibson, 2003), communication problems (Pearce, 1982) and many other negative emotions due to the cultural uncertainty (Goeldner \& Ritchie, 2008; $\mathrm{Ng}$ et al., 2007). The mediating role of quality of social contact in this model explains the underlying negative relationship between perceived cultural distance and travel attitude. Perceived cultural distance arouses tourist' motivation of novelty seeking, which may lead to positive travel attitude towards a destination (Hsu et al., 2010; Hung \& Patrick, 2011; Zatori, Smith \& Puczko, 2018). This statement is empirically supported by the mediator of the quantity of social contact. As reported in the findings, tourists are attracted by cultural differences in a destination and tended to contact a variety of residents to explore the local lifestyle, customs and other cultural attractions. The wide-ranging contact with the hosts, especially through service staff, enables tourists to be capsulised in a 'well-designed' and 'staged' experience (MacCannell, 2018). By such kind of 'proper' exploration, tourists' hold positive travel attitude towards the destination. To conclude, although the two arguments appeared contradictory, they captured diverse effects of perceived cultural distance on travel attitude via two different approaches and hence led to distinct consequences.

Considering the concept of tourist bubble, as described by Cohen (1972) and Jaakson (2004), social and cultural separation is like an environmental bubble, which creates a protective wall for the tourists from the host society. Such kind of bubble can influence tourists' travel experiences, perceptions and their attitudes towards the destinations. The current study concurred 
with the literature and further developed the concept by specifying the roles that different aspects of social contact play in the relationship. As shown in this study, social contact-mediated the relationship between perceived cultural distance and travel attitude positively and negatively. In that case, remaining in the cultural bubble may not necessarily lead to a negative attitude and decapsulating oneself out of the bubble may not guarantee a positive outcome. The result heavily depends on the variety and extent of the contact with the hosts in a destination.

\section{Theoretical contributions and practical implications}

This study is the first to introduce the tourist-host social contact into the debate of the relationship between perceived cultural distance and travel attitude and explained this relationship by considering direct and indirect effects. Previous studies have described predominantly the role of perceived cultural distance as either positive or negative. The incoherence has been challenged by different individual works but no convincing results have been achieved. The most insightful finding of this study is the confirmation of the relationship between perceived cultural distance and travel attitude as 'contact elastic'. The current study verified the simultaneous existence of positive and negative mediating effects of social contact. The relationship between perceived cultural distance and travel attitude depended largely on the different mediating roles of social contact, which served as a rubber band in the middle. To summarise, the quantity of contact may enhance the positive effect of perceived cultural distance on tourists' travel attitude, whereas the quality of contact may result in the negative effect of perceived cultural distance towards tourists' travel attitude. The study offered empirical support to paradoxical arguments and expanded the existing body of knowledge by introducing indirect effects to the arguable relationship. 
The study examined the role of tourist-host social contact as outcome and antecedent. Perceived cultural distance has diverse effects on different dimensions of tourist-host social contact. Not limited to the tourism realm, the co-existence of contrary effects of perceived cultural distance on social contact and the dynamic role of social contact in mediating the relationship between cultural distance and attitude may also help in understanding human beings' socialisation process and cultural determinism.

The study has certain implications for the government, operators and host societies. From the government's viewpoint, in addition to the economic benefits, tourism is expected to induce positive attitudes between tourists and hosts. Based on the discussion elaborated above, the effect of perceived cultural distance on tourists' travel attitude was determined heavily by the trade-off between the quantity and the quality of the contact with the hosts. Thus, this relationship should be utilised with caution given that the contact with the local hosts may not necessarily lead to the positive attitude and isolating oneself from interacting with the locals may not guarantee a negative outcome. Opportunities can be created for wide-ranging interactions, especially for service purposes, to achieve a sustainable relationship between tourists and hosts with different cultural backgrounds. Resident volunteers can be tapped in attractions and city centres to provide guidance and translations, join the service staff in different service outlets and participate in interactive cultural performances and festivals. While enjoying the advantages of the quantity of social contact, efforts should also be exerted, such as offering professional training to the service staff on a regular basis to minimise the negative effect of perceived cultural distance on the quality of social contact, leading to negative travel attitude.

In a tourism destination, actions can be taken to improve the tourist-host relationship and maintain the sustained growth of tourism development. For example, the support of local 
communities is a vital component to the successful maintenance of a good relationship with the tourists (Tasci \& Severt, 2017). The government can consider improving the residents' awareness of tourism through continuous tourism education (Malihah \& Setiyorini, 2014; Thyne, Watkins \& Yoshida, 2018). Such kind of education informs the hosts on the benefits of tourism and the behavioural and perceptional differences that residents may experience because of their different cultural backgrounds. With a tolerant and hospitable host environment, the sustainable tourist-host relationship can be nurtured naturally. Moreover, service-oriented social contact plays an important role in enhancing positive travel attitude, and thus, service staff training in service quality, handling cultural distance and expression of hospitality should be carried out by corresponding operators to ensure a pleasant experience for the tourists. From a tourist's viewpoint, familiarisation of the destination's lifestyle, behavioural patterns and communication culture before departure can facilitate their enjoyable encounter with the hosts during their stay, leading to a positive attitude towards the destination.

With many countries and territories now recognising tourism as a substantial development option and one with considerable economic benefits, governments are often reluctant to place limitations on inbound tourism numbers. Many long-standing issues in the tourism literature, such as carrying capacity, limit growth, and social and environmental concerns are subordinated to economic considerations. However, tourism remains a non-essential purchase, which is substituted easily for other products and services or within the tourism destination choice spectrum. Moreover, tourist spots have many potential competing destinations. For this reason, governments and tourism destinations should consider the social relationship between residents and tourists. Ignoring concerns of residents on the volume or nature of tourist activities can ferment ill-feeling and antipathy towards tourism and tourists, 
causing them to reach the stage where tourists choose alternative destinations with consequent economic effects.

\section{CONCLUSION AND LIMITATIONS}

The present study examined empirically the relationships among perceived cultural distance, tourist-host social contact and travel attitude by adopting a mixed-methods approach and developing a multi-dimensional social contact between tourists and hosts. Building on those direct relationships, the study investigated further the mediating effect of different dimensions of social contact between perceived cultural distance and travel attitude. The results indicated that perceived cultural distance can affect tourists' travel attitude directly and indirectly. A larger perceived cultural distance can lead directly to a more favourable travel attitude. Meanwhile, perceived cultural distance can affect tourists' travel attitude positively by involving more tourist participation in a variety of contacts with the hosts, especially with tourism contact points. However, the perceived cultural distance may generate negative quality of contact and such kind of unfavourable emotions may lead to negative travel attitude. The findings confirmed theoretically the direct and indirect effects of perceived cultural distance on travel attitude and identified for the first time the mediating effect of tourist-host social contact in this relationship. The study offered a new outlook to explain the ambiguous viewpoints on the effect of cultural distance on travel attitude. The study also provided practical suggestions for destination policymakers, tourism practitioners and local communities regarding how to handle the 'contact elastic' relationship to maintain a favourable and sustainable tourist-host bond.

As with other studies, this study needs to be considered with the following limitations. First, the research context for the current study was between Hong Kong and mainland China, 
which has a small and supplementary cultural distance. In that case, results obtained from this cultural context may vary from cases with large and intolerable cultural differences. Second, the tourist-host social contact adopted in this study referred to the general mass tourists with broad and diverse travel interests and patterns. Different markets of tourism, for instance, voluntourism, ecotourism, cultural tourism and B-Leisure (Business + Leisure) tourism may generate different contact patterns and quality. In that case, their effects on the relationship between perceived cultural distance and travel attitude may differ. Taking this study as the starting point, future studies could explore the proposed cultural distance-social contact-travel attitude relationship in cross-country cultural contexts to examine the applicability of this model. Furthermore, because of the different contact parties and patterns, different niche markets should undergo specialised investigation to explore any nuanced findings in different market segments. Finally, other potential outcomes caused by cultural distance and social contacts between tourists and hosts, such as travel experience, destination immersion and perceived destination image can be integrated into the current model to explore broader social-cultural effects. 


\section{REFERENCES}

Ahn, M. J., \& McKercher, B. (2015). The effect of cultural distance on tourism: A study of international visitors to Hong Kong. Asia Pacific Journal of Tourism Research, 20(1), 94-113.

Ajzen, I. (1988). Attitude, Personality and Behavior. Milton Keynes, UK: Open University Press.

Ajzen, I. (1991). The theory of planned behavior. Organizational Behavior and Human Decision Processes, 50, 179-211.

Aleshinloye, K. D., Fu, X., Ribeiro, M. A., Woosnam, K. M., \& Tasci, A. D. (2020). The influence of place attachment on social distance: Examining mediating effects of emotional solidarity and the moderating role of interaction. Journal of Travel Research, $59(5), 828-849$.

Allport, G. W. (1979). The nature of prejudice. Reading, MA: Addison-Wesley Pub.

Amir, Y. \& Ben-Ari, R. (1985). International tourism, ethnic contact, and attitude change. Journal of Social Issues, 41 (3), 105-115.

Anastasopoulos, P. G. (1992). Tourism and attitude change: Greek tourists visiting Turkey. Annals of tourism research, 19(4), 629-642.

Assaker, G., Huang, S., \& Hallak, R. (2012). Applications of partial least squares structural equation modeling in tourism research: A methodological review. Tourism Analysis, $17(5), 679-686$. 
Bagozzi, R. P. \& Burnkrant, R. E. (1979). Attitude measurement and behavior change: A reconsideration of attitude organization and its relationship to behavior. Advances in Consumer Research, 6, 295-302.

Bagozzi, R. P., \& Kimmel, S. K. (1995). A comparison of leading theories for the prediction of goal directed behaviours. British Journal of Social Psychology, 34 (4), 437-461.

Barthes, R. (1973). Mythologies. London: Paladin.

Beard, J. G. \& Ragheb, M. G. (1983). Measuring leisure motivation. Journal of Leisure Research, 15 (3), 219-228.

Binder, J., Zagefka, H., Brown, R., Funke, F., Kessler, T., Mummendey, A., ... \& Leyens, J. P. (2009). Does contact reduce prejudice or does prejudice reduce contact? A longitudinal test of the contact hypothesis among majority and minority groups in three European countries. Journal of personality and social psychology, 96(4), 843.

Bochner, S. (1982). The Social Psychology of Cross-Cultural Relations. In Cultures in Contact: Studies in Cross-Cultural Interaction, edited by Stephen Bochner, 5-29. Oxford: Pergamon.

Braun, V., \& Clarke, V. (2006). Using qualitative analysis in psychology. Qualitative Research in Psychology, 3(2), 77-101.

Brewer, M. B. \& Campbell, D. T. (1976). Ethnocentrism and intergroup attitudes: East African evidence. New York: Sage.

Byrne, B. (2010). Structural Equation Modeling with AMOS: Basic Concepts, Applications, and Programming. $2^{\text {nd }}$ ed. New York: Taylor \& Francis. 
Carneiro, M. J., \& Eusébio, C. (2015). Host-tourist interaction and impact of tourism on residents' Quality of Life. Tourism \& Management Studies, 11(1), 25-34.

Carneiro, M. J., Eusébio, C., \& Caldeira, A. (2018). The influence of social contact in residents' perceptions of the tourism impact on their quality of life: A structural equation model. Journal of Quality Assurance in Hospitality \& Tourism, 19(1), 1-30.

Caulkins, D. D. (1999). Is Mary Douglas's grid/group analysis useful for cross-cultural research?. Cross-Cultural Research, 33(1), 108-128.

Chen, Y., Schuckert, M., Song, H., \& Chon, K. (2016). Why Can Package Tours Hurt Tourists? Evidence from China's Tourism Demand in Hong Kong. Journal of Travel Research, 55(4), 427-439.

China National Tourism Administration of P.R.C. (2017). The Yearbook of China Tourism Statistics 2016. Beijing: China Travel and Tourism Press.

Choi, H. S. C., \& Sirakaya, E. (2005). Measuring residents' attitude toward sustainable tourism: Development of sustainable tourism attitude scale. Journal of Travel Research, 43(4), 380-394.

Cohen, E. (1972). Toward a sociology of international tourism. Social Research, 39 (1), 164-182.

Cohen, E. (1979). A phenomenology of tourist experiences. Sociology, 13 (2), 170-201.

Cohen, E. (2007). 'Authenticity’ in tourism studies: Aprés la lutte. Tourism Recreation Research, 32(2), 75-82.

Crompton, J. L. (1979). Motivations for pleasure vacation. Annals of Tourism Research, 6 (4), 408- 424. 
Cusher, K. \& Brislin (1996). Intercultural interactions: A practical guide. Thousand Oaks, CA: Sage.

Daly, J., Kellehear, A., \& Gliksman, M. (1997). The Public Health Researcher: A Methodological Guide. Oxford University Press.

Dewar, K., Meyer, D. \& Li, W. M. (2001). Harbin, lanterns of ice, sculptures of snow. Tourism Management, 22 (5), 523-532.

Douglas, M. (1982). In the Active Voice. Routledge: London.

Esiyok, B., Çakar, M., \& Kurtulmuşoğlu, F. B. (2017). The effect of cultural distance on medical tourism. Journal of Destination Marketing \& Management, 6(1), 66-75.

Fan, D. X., Hsu, C. H., \& Lin, B. (2020). Tourists' experiential value co-creation through online social contacts: Customer-dominant logic perspective. Journal of Business Research, 108, 163-173.

Fan, D. X., Liu, A., \& Qiu, R. T. (2017). The Impact of the Culture Distance on Tourism Demand--An Econometric Method from a Global Perspective. In: Advances in Tourism Marketing Conferences 2017 Proceedings, 6-9 September 2017 Casablanca, Morocco.

Fan, D. X., Zhang, H. Q., Jenkins, C. L., \& Lin, P. M. (2017b). Does Tourist-Host Social Contact Reduce Perceived Cultural Distance?. Journal of Travel Research, 56(8), 9981010.

Fan, D. X., Zhang, H. Q., Jenkins, C. L., \& Tavitiyaman, P. (2017a). Tourist typology in social contact: An addition to existing theories. Tourism Management, 60, 357-366.

Feather, N. (1980). Similarity of Value Systems within the Same Nation: Evidence from Australia and Papua New Guinea. Australian Journal of Psychology, 32 (1), 17-30. 
Fishbein, M. A. \& Ajzen, I. (1975). Belief, attitude, intention and behavior: An introduction to theory and research. Reading, MA: Addison-Wesley.

Fulbright, J. W. (1976). The most significant and important activity I have been privileged to engage in during my years in the Senate. The Annals of the American Academy of Political and Social Science, 424, 1-5.

Goeldner, C. R. \& Ritchie, J. R. (2008). Tourism: Principles, practices, philosophies. John Wiley \& Sons, Inc. Retrieved 15 October 2013, from http://www.myilibrary.com?ID=176679

Hair, J. F., Ringle, C. M., \& Sarstedt, M. (2011). PLS-SEM: Indeed a silver bullet. Journal of Marketing theory and Practice, 19(2), 139-152.

Hair, J.F., Black, W., Babin, B. \& Anderson, R. (2010). Multivariate Data Analysis, PrenticeHall.

Han, H., Hsu, L. T. \& Sheu, C. (2010). Application of the Theory of Planned Behavior to green hotel choice: Testing the effect of environmental friendly activities. Tourism Management, 31(3), 325-334.

Henseler, J., Hubona, G., \& Ray, P. A. (2016). Using PLS path modeling in new technology research: updated guidelines. Industrial Management \& Data Systems, 116(1), 2-20.

Hofstede, G., Hofstede, G. J., \& Minkov, M. (2010). Cultures and Organizations: Software of the Mind. Revised and expanded 3rd Edition. N.-Y.: McGraw-Hill.

Hong Kong Census and Statistics Department (2015). Socio-economic Characteristics and Consumption Expenditure of Hong Kong Residents Making Personal Travel to the Mainland of China, 2014. Retrieved July 11, 2017 from Hong Kong Special 
Administrative Region Web site:

http://www.statistics.gov.hk/pub/B71511FB2015XXXXB0100.pdf

Hsu, C. H., \& Huang, S. (2012). An extension of the theory of planned behavior model for tourists. Journal of Hospitality \& Tourism Research, 36(3), 390-417.

Hsu, C. H.C., Kang, S. K. \& Lam, T. (2006). Reference group influences among Chinese travelers. Journal of Travel Research, 44 (4), 474-484.

Hsu, C.H.C., Cai, L., \& Li, M. (2010). Expectation, motivation, and attitude: A tourist behavioral model. Journal of Travel Research, 49 (3), 282-296.

Huang, J., \& Hsu, C. H. (2010). The impact of customer-to-customer interaction on cruise experience and vacation satisfaction. Journal of Travel Research, 49(1), 79-92.

Hung, K. L. \& Petrick, J. F. (2011). Why do you cruise? Exploring the motivations for taking cruise holidays and the construction of a cruising motivation scale. Tourism Management, 32 (2), 386- 393.

Jaakson, R. (2004). Beyond the tourist bubble?: Cruiseship passengers in port. Annals of tourism research, 31(1), 44-60.

Joo, D., Tasci, A. D. A., Woosnam, K. M., Maruyama, N. U., Hollas, C. R., \& Aleshinloye, K. D. (2018). Residents' attitude towards domestic tourists explained by contact, emotional solidarity and social distance. Tourism Management, 64, 245-257.

Kamal, A. \& Maruyama, G. (1990). Cross-cultural contact and attitudes of Qatari students in the United States. International Journal of Intercultural Relations, 14 (2), 123-134. 
Kawakami, K., Dovidio, J. F., Moll, J., Hermsen, S., \& Russin, A. (2000). Just say no (to stereotyping): Effects of training in the negation of stereotypic associations on stereotype activation. Journal of personality and social psychology, 78(5), 871.

Kirillova, K., Lehto, X., \& Cai, L. (2015). Volunteer tourism and intercultural sensitivity: The role of interaction with host communities. Journal of Travel \& Tourism Marketing, 32(4), $382-400$.

Lam, T., \& Hsu, C.H.C. (2006). Predicting behavioral intention of choosing a travel destination. Tourism Management, 27, 589- 599.

Lee, C. H., Chen, H. S., Liou, G. B., Tsai, B. K., \& Hsieh, C. M. (2018). Evaluating International Tourists’ Perceptions on Cultural Distance and Recreation Demand. Sustainability, $10(12), 4360$.

Lepp, A. \& Gibson, H. (2003). Tourist roles, perceived risk and international tourism. Annals of Tourism Research, 30 (3), 606-624.

Leung, D., Woo, G. J., \& Ly, T. P. (2013). The Effects of Physical and Cultural Distance on Tourist Satisfaction: A Case Study of Local-Based Airlines, Public Transportation, and Government Services in Hong Kong. Journal of China Tourism Research, 9(2), 218-242.

Levine, D. N. (1977). Simmel at a distance: On the history and systematics of the sociology of the stranger. Sociological Focus, 10(1), 15-29.

Li, M., Zhang, H., Xiao, H., \& Chen, Y. (2015). A Grid-group Analysis of Tourism Motivation. International Journal of Tourism Research, 17(1), 35-44. 
Li, Y. Q., \& Liu, C. H. (2020). Impact of cultural contact on satisfaction and attachment: mediating roles of creative experiences and cultural memories. Journal of Hospitality Marketing \& Management, 29(2), 221-245.

Lin, P. M., Fan, D. X., Zhang, H. Q., \& Lau, C. (2019). Spend less and experience more: Understanding tourists' social contact in the Airbnb context. International Journal of Hospitality Management, 83, 65-73.

Lincoln, Y. S., \& Guba, E. G. (1985). Naturalistic inquiry. Beverly Hills, CA: Sage Publications.

Liu, H., Li, X. R., Cárdenas, D. A., \& Yang, Y. (2018). Perceived cultural distance and international destination choice: The role of destination familiarity, geographic distance, and cultural motivation. Journal of Destination Marketing \& Management, 9, 300-309.

MacCannell, D. (1973). Staged authenticity: Arrangements of social space in tourist settings. American journal of Sociology, 79(3), 589-603.

MacCannell, D. (2018). Staged authenticity: Arrangements of social space in tourist settings. In Gmelch, S. B., \& Kaul, A. ed. Tourists and Tourism: A Reader. Waveland Press.

Malihah, E., \& Setiyorini, H. P. D. (2014, October). Tourism education and edu-tourism development: Sustainable tourism development perspective in education. In The 1st International Seminar on Tourism (ISOT)-“Eco-Resort and Destination Sustainability: Planning, Impact, and Development" (pp. 1-7).

Martin, B. A., Jin, H. S., \& Trang, N. V. (2017). The entitled tourist: The influence of psychological entitlement and cultural distance on tourist judgments in a hotel context. Journal of Travel \& Tourism Marketing, 34(1), 99-112. 
Mayo, E. J. \& Jarvis, L. P. (1981). The psychology of leisure travel: Effective marketing and selling of travel services. Boston: CBI Publishing Company Inc.

Mazanec, J. A., Crotts, J. C., Gursoy, D., \& Lu, L. (2015). Homogeneity versus heterogeneity of cultural values: An item-response theoretical approach applying Hofstede's cultural dimensions in a single nation. Tourism Management, 48, 299-304.

Mckercher, B. \& Chow, B. (2001). Cultural distance and participation in cultural tourism. Pacific Tourism Review, 5 (1), 23-32.

Mckercher, B. \& Cros, H. D. (2003). Testing a cultural tourism typology. International Journal of Tourism Research, 5 (1), 45-58.

Milman, A., Reichel, A., \& Pizam, A. (1990). The impact of tourism on ethnic attitudes: the Israeli-Egyptian case. Journal of Travel Research, 29(2), 45-49.

Mo, C. M., Howard, D. R., \& Havitz, M. E. (1993). Testing an international tourist role typology. Annals of Tourism Research, 20(2), 319-335.

Moufakkir, O. (2011). The role of cultural distance in mediating the host gaze. Tourist Studies, 11(1), 73-89.

Moutinho, L. (1987). Consumer behaviour in tourism. European Journal of Marketing. October, $5-44$.

Ng, S. I., Lee, J. A. \& Soutar, G. N. (2007). Tourists' intention to visit a country: The impact of cultural distance. Tourism Management, 28 (6), 1497-1506.

Nyaupane, G. P., Timothy, D. J., \& Poudel, S. (2015). Understanding tourists in religious destinations: A social distance perspective. Tourism Management, 48, 343-353. 
Pearce, P. L. (1982). Tourists and their hosts: Some social and psychological effects of intercultural contact. In S. Bochner Cultures in contact: Studies in cross-cultural interaction (p. 199). New York: Pergamon Press Ltd.

Pettigrew, T. F. (1998). Intergroup contact theory. Annual Review of Psychology, 49(1), 65-85.

Pizam, A. (1996). Does tourism promote peace and understanding between unfriendly nations? In Tourism, Crime and International Security Issues, edited by A. Pizam and Y. Mansfeld, 203-13. Chichester, UK: Wiley.

Pizam, A., Jafari, J., \& Milman, A. (1991). Influence of tourism on attitudes: US students visiting USSR. Tourism Management, 12(1), 47-54.

Pizam, A., Uriely, N. \& Reichel, A. (2000). The intensity of tourist-host social relationship and its effects on satisfaction and change of attitudes: The case of working tourists in Israel. Tourism Management, 21 (4), 395-406.

Poon, K. Y., \& Huang, W. J. (2017). Past experience, traveler personality and tripographics on intention to use Airbnb. International Journal of Contemporary Hospitality Management. 29(9), 2425-2443.

Potter, C. C. (1989). What is culture: And can it be useful for organisational change agents?. Leadership \& Organization Development Journal.

Ragheb, M. G. \& Beard, J. G. (1982). Measuring leisure attitudes. Journal of Leisure Research, $14(2), 155-162$.

Rasoolimanesh, S. M., Ringle, C. M., Jaafar, M., \& Ramayah, T. (2017). Urban vs. rural destinations: Residents' perceptions, community participation and support for tourism development. Tourism Management, 60, 147-158. 
Reisinger, Y. \& Turner, L. (1998a). Cross-cultural differences in tourism: A strategy for tourism marketers. Journal of Travel and Tourism Marketing, 7 (4), 79-106.

Reisinger, Y. \& Turner, L. (1998b). Cultural differences between Mandarin-speaking tourists and Australian hosts and their impact on cross-cultural tourist-host interaction. Journal of Business Research, 42, 175-187.

Reisinger, Y. \& Turner, L. W. (2002a). Cultural differences between Asian tourist markets and Australian hosts, Part 1. Journal of Travel Research, 40 (3), 295-315.

Reisinger, Y. \& Turner, L. W. (2002b). Cultural differences between Asian tourist markets and Australian hosts, Part 2. Journal of Travel Research, 40 (4), 385-395.

Robinson, G., \& Nemetz, L. (1988). Cross-cultural understanding. Harlow, UK: Prentice Hall.

Rosenberg, M. J., Hovland, C. I., McGuire, W. J., Abelson, R. P. \& Brehm, J. W. (1960). Attitude organization and change. New Haven: Yale University Press.

Rothman, R. A. (1978). Residents and transients: Community reaction to seasonal visitors. Journal of Travel Research, 16(3), 8-13.

Ryan, C. \& Glendon, I. (1998). Application of leisure motivation scale to tourism. Annals of Tourism Research, 25 (1), 169- 184.

Shen, H., Luo, J., \& Zhao, A. (2017). The sustainable tourism development in Hong Kong: An analysis of Hong Kong residents' attitude towards Mainland Chinese tourist. Journal of Quality Assurance in Hospitality \& Tourism, 18(1), 45-68.

Siehl, C. \& Martin, J. (1985). Measuring organizational culture. University of Southern California Center for Effective Organizations Paper, G 85-11. Los Angeles: University of Southern California. 
Sin, H. L. (2009). Volunteer tourism: “Involve me and I will learn"? Annals of Tourism Research, 36(3), 480-501.

Smith, V. L. (1989). Hosts and Guests: The Anthropology of Tourism. Philadelphia: University of Pennsylvania Press.

Sparks, B. \& Pan, G. W. (2009). Chinese outbound tourists: Understanding their attitudes, constraints and use of information sources. Tourism Management, 30 (4), 483-494.

Spradley, J. P. \& Philips, M. (1972). Culture and stress: A quantitative analysis. American Anthropologist, 74, 518-529.

Sung, H. H., Morrison, A. M., Hong, G. S., \& O’Leary, J. T. (2001). The effects of household and trip characteristics on trip types: a consumer behavioral approach for segmenting the US domestic leisure travel market. Journal of Hospitality \& Tourism Research, 25(1), $46-68$.

Tasci, A. D. A. (2009). Social distance: The missing link in the loop of movies, destination image, and tourist behavior?. Journal of Travel Research, 47(4), 494-507.

Tasci, A. D. A., \& Severt, D. (2017). A triple lens measurement of host-guest perceptions for sustainable gaze in tourism. Journal of Sustainable Tourism, 25(6), 711-731.

Thrane, C. (2016). The determinants of Norwegians' summer tourism expenditure: foreign and domestic trips. Tourism Economics, 22(1), 31-46.

Thyne, M., Lawson, R., \& Todd, S. (2006). The use of conjoint analysis to assess the impact of the cross-cultural exchange between hosts and guests. Tourism Management, 27(2), 201213. 
Thyne, M., Watkins, L., \& Yoshida, M. (2018). Resident perceptions of tourism: The role of social distance. International Journal of Tourism Research, 20(2), 256-266.

Tran, X., \& Ralston, L. (2006). Tourist preferences influence of unconscious needs. Annals of Tourism Research, 33(2), 424-441.

Triandis, H. C. (1977). Subjective culture and interpersonal relations across cultures. Annals of New York Academy of Sciences, 285, Issues in Cross-Cultural Research, 418-434.

Triandis, H. C. (1994). Culture and social behavior. New York: McGraw-Hill.

Wang, J. \& Ritchie, B. W. (2012). Understanding accommodation managers' crisis planning intention: An application of the theory of planned behaviour. Tourism Management, $33(5), 1057-1067$.

Ward, C., Bochner, S., \& Furnham, A. (2005). The Psychology of Culture Shock. Routledge.

Wei, L., Crompton, J. L. \& Reid, L. M. (1989). Cultural conflicts: Experiences of US visitors to China. Tourism Management, 10 (4), 322-332.

Woosnam, K. M., \& Aleshinloye, K. D. (2013). Can tourists experience emotional solidarity with residents? Testing Durkheim's model from a new perspective. Journal of Travel Research, 52(4), 494-505.

Woosnam, K. M., \& Lee, Y. J. (2011). Applying social distance to voluntourism research. Annals of Tourism Research, 38(1), 309-313.

Yang, Y., Liu, H., \& Li, X. (2018). The world is flatter? Examining the relationship between cultural distance and international tourist flows. Journal of Travel Research, 0047287517748780 . 
Ye, B., Zhang, H.Q., Shen, H. J., \& Goh, C. (2014). Does social identity affect residents' attitude toward tourism development? An evidence from the relaxation of the Individual Visit Scheme. International Journal of Contemporary Hospitality Management, 26(6), 907929.

Yilmaz, S. S., \& Tasci, A. D. (2015). Circumstantial impact of contact on social distance. Journal of Tourism and Cultural Change, 13(2), 115-131.

Yu, J. Y. \& Lee, T. J. (2014). Impact of tourists' intercultural interactions. Journal of Travel Research, 53 (2), 225- 238.

Zatori, A., Smith, M. K., \& Puczko, L. (2018). Experience-involvement, memorability and authenticity: The service provider's effect on tourist experience. Tourism Management, 67, 111-126.

Zhang, H.Q., \& Lam, T. (1999). An analysis of Mainland Chinese visitors' motivations to visit Hong Kong. Tourism Management, 20(5), 587-594. 
Table 1. Demographics of Samples $(n=635)$

\begin{tabular}{|c|c|c|c|}
\hline Demographics & $\%$ & Demographics & $\%$ \\
\hline Gender & & Marital Status & \\
\hline Male & 56.98 & Single & 32.32 \\
\hline Female & 43.02 & Married with child(ren) & 52.80 \\
\hline Age & & Married without child(ren) & 13.76 \\
\hline $18-24$ & 10.53 & Others & 1.12 \\
\hline $25-34$ & 23.92 & Relation to the tourism industry & \\
\hline $35-44$ & 27.11 & Yes & 7.09 \\
\hline $45-64$ & 34.13 & No & 85.67 \\
\hline 65 or above & 4.31 & Not applicable & 7.24 \\
\hline Education & & Background of living in mainland Chin & efore \\
\hline Primary or below & 0.95 & Yes & 31.26 \\
\hline Secondary school & 14.74 & No & 68.74 \\
\hline Diploma/Certificate & 14.90 & Which immigrant generation are you? & \\
\hline Sub-degree course & 3.01 & First & 12.91 \\
\hline Bachelor or above & 66.40 & Second & 38.90 \\
\hline Monthly Household Income (HKD) & & Third and above & 17.01 \\
\hline $0-9,999$ & 0.34 & I do not know & 8.82 \\
\hline $10,000-19,999$ & 7.91 & Not applicable & 22.36 \\
\hline 20,000-29,999 & 7.74 & Mode of Tour & \\
\hline 30,000-39,999 & 11.95 & Individual travellers & 79.37 \\
\hline $40,000-49,999$ & 9.09 & Package tour & 20.63 \\
\hline $50,000-59,999$ & 12.46 & Travel Times & \\
\hline 60,000 or above & 36.20 & $1-3$ times & 23.46 \\
\hline Not applicable & 14.31 & 4-6 times & 20.63 \\
\hline Occupation & & 7-9 times & 10.87 \\
\hline Managers and administrators & 32.91 & 10-19 times & 13.23 \\
\hline Professionals & 29.41 & 20 times or more & 31.81 \\
\hline Associate professionals & 3.82 & Length of Stay & \\
\hline Clerks & 7.00 & $1-2$ days & 11.34 \\
\hline Service workers and shop sales workers & 3.97 & $3-5$ days & 64.25 \\
\hline Craft and related workers & 2.23 & $6-8$ days & 15.75 \\
\hline $\begin{array}{l}\text { Plant and machine operators and } \\
\text { assemblers }\end{array}$ & 0.48 & 9 days or more & 8.66 \\
\hline Elementary occupations & 0.79 & & \\
\hline Retired & 6.04 & & \\
\hline Students & 7.79 & & \\
\hline Not applicable & 5.56 & & \\
\hline
\end{tabular}


Table 2. Results of the Measurement Model $(n=635)$

\section{Constructs and Items}

\begin{tabular}{cccc}
$\begin{array}{c}\text { Standardized } \\
\text { Factor } \\
\text { Loading }\end{array}$ & $\begin{array}{c}\text { Composite } \\
\text { Reliability }\end{array}$ & rho A & $\begin{array}{c}\text { Average Variance } \\
\text { Extracted (AVE) }\end{array}$ \\
\hline
\end{tabular}

Perceived Cultural Distance (PCD)

Cultural Retention (CR)

People in mainland China and Hong Kong have different traditional customs.

People in mainland China and Hong Kong have differences in terms of richness of traditional customs.

People in mainland China and Hong Kong have a different sense of culture retention.

Behavioural Characteristics (BC)

People in mainland China and Hong Kong are different at the civilization level.

People in mainland China and Hong Kong have different privacy protection.

People in mainland China and Hong Kong have different hygiene standards.

Social Characteristics (SC)

People in mainland China and Hong Kong are different in their way of communication.

People in mainland China and Hong Kong are different in their way of making friends.

Social-Oriented Contact (Social OC)

Interaction with the locals when travelling together (showing around)

Interaction with the locals in participating performance

0.810

0.659

0.587

0.803

0.782

0.710

Interaction with the locals by exchanging gifts

Interaction with the locals by experiencing their customs

Interaction with the locals by enquiring or receiving help from them

Interaction with the locals when there is a conflict

0.829

0.703

0.619

0.813

0.787

0.758

Interaction with the locals by visiting their homes

Service-Oriented Contact (Service OC)

0.906

0.875

0.658

0.879

0.848

Interaction with the service personnel while shopping

0.812

Interaction with the service personnel in accommodation

0.775

Interaction with the service personnel in transportation

0.734 
intense

equal

cooperative

Travel Attitude (TA)

favourable

good

satisfying

worthwhile

right

fascinating

fun

exciting

arousing

positive

desirable

enjoyable
0.768

0.734

0.695

$\begin{array}{lll}0.956 & 0.950 & 0.644\end{array}$

0.849

0.842

0.831

0.821

0.820

0.814

0.809

0.797

0.783

0.774

0.744

0.739 
Table 3. Results of the Heterotrait-Monotrait Ratio of Correlations (HTMT)

\begin{tabular}{|c|c|c|c|c|c|c|c|}
\hline & $\begin{array}{c}\text { Travel } \\
\text { Attitude } \\
\end{array}$ & $\begin{array}{c}\text { Behavioural } \\
\text { Characteristics }\end{array}$ & $\begin{array}{c}\text { Cultural } \\
\text { Retention }\end{array}$ & $\begin{array}{c}\text { Quality of } \\
\text { Contact }\end{array}$ & $\begin{array}{c}\text { Social } \\
\text { Characteristics }\end{array}$ & $\begin{array}{c}\text { Service-Oriented } \\
\text { Contact }\end{array}$ & $\begin{array}{c}\text { Social-Oriented } \\
\text { Contact }\end{array}$ \\
\hline Travel Attitude & - & & & & & & \\
\hline $\begin{array}{c}\text { Behavioural } \\
\text { Characteristics }\end{array}$ & 0.062 & - & & & & & \\
\hline $\begin{array}{l}\text { Cultural } \\
\text { Retention }\end{array}$ & 0.095 & 0.623 & - & & & & \\
\hline $\begin{array}{c}\text { Quality of } \\
\text { Contact }\end{array}$ & 0.728 & 0.177 & 0.093 & - & & & \\
\hline $\begin{array}{c}\text { Social } \\
\text { Characteristics }\end{array}$ & 0.051 & 0.565 & 0.581 & 0.155 & - & & \\
\hline $\begin{array}{c}\text { Service-Oriented } \\
\text { Contact }\end{array}$ & 0.283 & 0.244 & 0.113 & 0.284 & 0.103 & - & \\
\hline $\begin{array}{c}\text { Social-Oriented } \\
\text { Contact }\end{array}$ & 0.205 & 0.188 & 0.062 & 0.241 & 0.055 & 0.688 & - \\
\hline
\end{tabular}

Note: All the HTMTs are significantly less than the unit at 5\% significant level. 
Table 4. Results of the Path Analysis and Hypotheses Testing

\begin{tabular}{cclcccc}
\hline $\begin{array}{c}\text { Hypotheses } \\
\text { Path }\end{array}$ & Construct & Path & Construct & Coefficient & P & Results \\
\hline H1a and H1b & Perceived Cultural Distance & & Travel Attitude & 0.067 & 0.037 & H1a Supported \\
H2a and H2b & Social-Oriented Contact & & Travel Attitude & 0.002 & 0.968 & H2a Partially \\
& Service-Oriented Contact & & Travel Attitude & 0.091 & 0.038 & Supported \\
& Quality of Contact & & Travel Attitude & 0.628 & 0.000 & \\
H3 & Perceived Cultural Distance & & Social-Oriented Contact & 0.092 & 0.020 & Partially \\
& Perceived Cultural Distance & & Service-Oriented Contact & 0.155 & 0.000 & Supported \\
& Perceived Cultural Distance & & Quality of Contact & -0.128 & 0.002 & \\
\hline
\end{tabular}


Table 5. Mediating Effects in the Structural Model

\begin{tabular}{|c|c|c|c|c|c|c|c|c|c|}
\hline $\begin{array}{l}\text { Hypothesis } \\
\text { Path }\end{array}$ & Construct & Path & Construct & $\begin{array}{l}\text { Direct } \\
\text { Effect }\end{array}$ & Indire & t Effect & & $\begin{array}{l}\text { Total } \\
\text { Effect }\end{array}$ & Result \\
\hline \multirow{3}{*}{ H4 } & \multirow{3}{*}{$\begin{array}{c}\text { Perceived } \\
\text { Cultural } \\
\text { Distance }\end{array}$} & & \multirow{3}{*}{$\begin{array}{l}\text { Travel } \\
\text { Attitude }\end{array}$} & \multirow{3}{*}{$\begin{array}{c}0.067 \\
(0.029)\end{array}$} & $\begin{array}{l}\text { Social-Oriented } \\
\text { Contact }\end{array}$ & $\begin{array}{c}0.000 \\
(0.951)\end{array}$ & \multirow{3}{*}{$\begin{array}{l}-0.066 \\
(0.011)\end{array}$} & \multirow{3}{*}{$\begin{array}{c}0.001 \\
(0.978)\end{array}$} & \multirow{3}{*}{ Supported } \\
\hline & & & & & $\begin{array}{l}\text { Service-Oriented } \\
\quad \text { Contact }\end{array}$ & $\begin{array}{c}0.014 \\
(0.016)\end{array}$ & & & \\
\hline & & & & & $\begin{array}{l}\text { Quality of } \\
\text { Contact }\end{array}$ & $\begin{array}{l}-0.080 \\
(0.001)\end{array}$ & & & \\
\hline
\end{tabular}

Note: Figures in parenthesis are $\mathrm{p}$ values. 


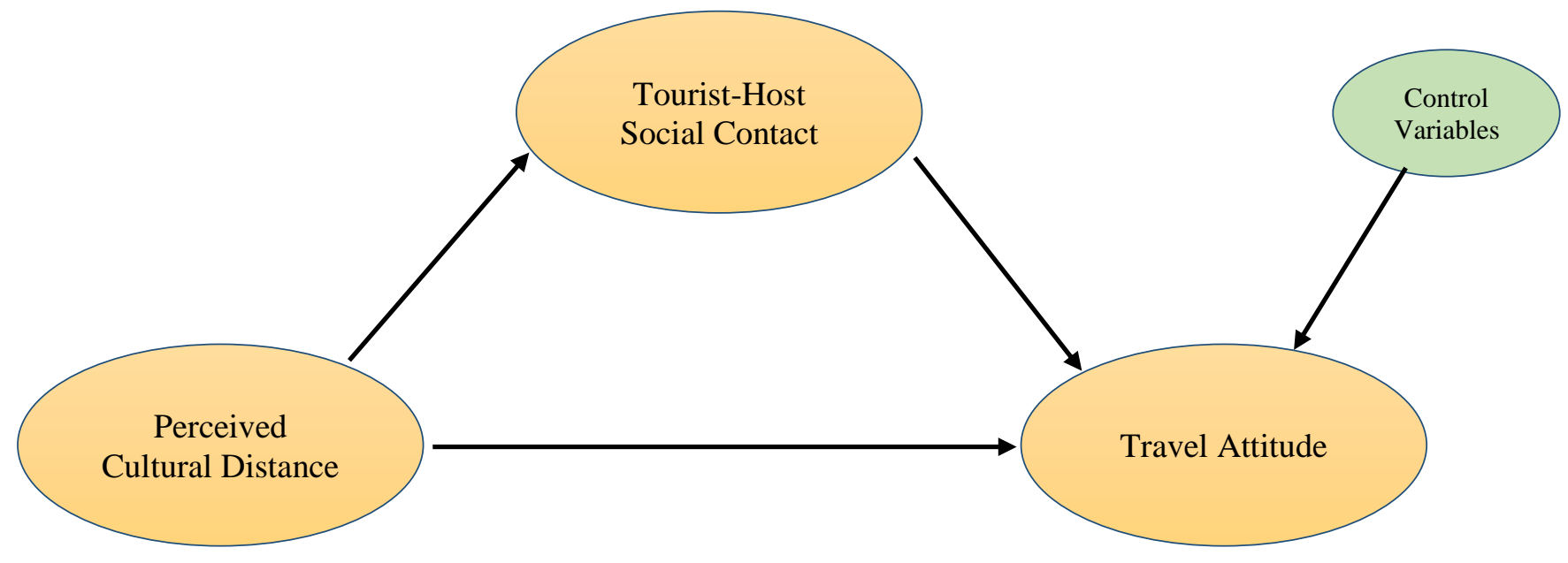

Figure 1. Theoretical Model of the Study 


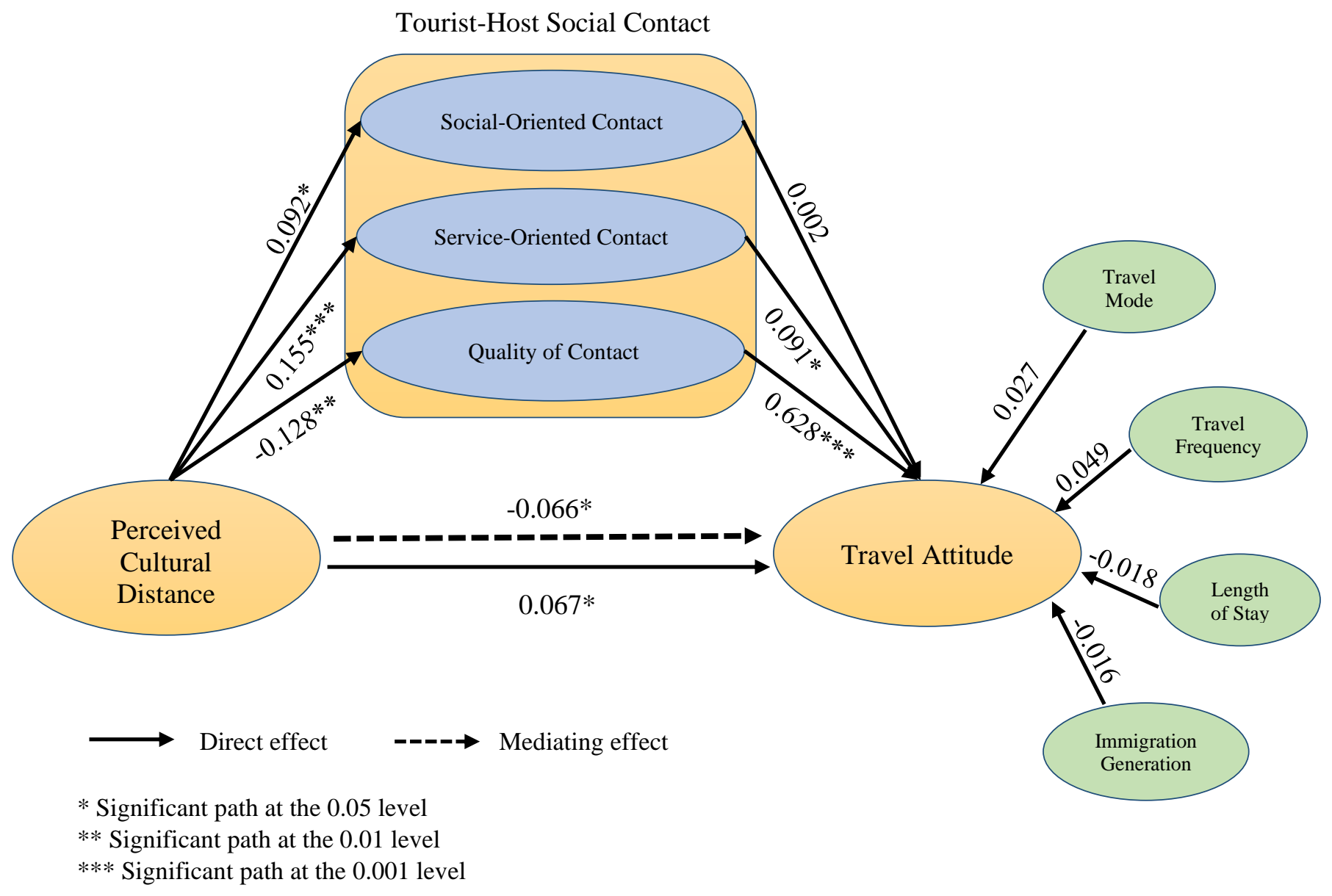

Figure 2. Final Structural Model with Standardized Path Coefficients 